\title{
The production of a bactericidal monoglyceride in staphylococcal abscesses
}

\author{
H. D. ENGLER* and F. A. KAPRAL $\dagger$
}

Department of Medical Microbiology and Immunology, The Ohio State University, Columbus, Ohio 43210, USA

\begin{abstract}
Summary. The treatment of abscess homogenates with calcium ionophores stimulated the production of a bactericidal lipid with properties indistinguishable from those of a previously unidentified bactericidal lipid that had been detected in staphylococcal abscesses. The lipid was identified as a monoglyceride by thin layer chromatography. It resembled the unidentified lipid in that it had a high specific activity, exhibited differential activity, was inhibited by Staphylococcus aureus $\delta$ toxin, lecithin and $\mathrm{Ca}^{++}$, and its activity was reduced by oxidation. Stimulation of monoglyceride production by calcium ionophore requires the joint presence of components from the sedimented and supernatant fractions of abscess homogenates, and was not produced if boiled homogenate was used. The addition of verapamil interfered with the production of monoglyceride in homogenates treated with calcium ionophore. Monoglyceride was produced only in abscess homogenates and not in homogenates of other normal tissues or tissues taken from mice infected with $S$. aureus. Calcium ionophore could be replaced by inositol triphosphate, suggesting that monoglyceride production involved the release of calcium from intracellular stores. The 2-monoglyceride was the form originally produced in abscess homogenates, but this spontaneously isomerised to the 1-monoglyceride. The fatty-acid moiety of the monoglyceride consisted primarily of 16:0 and 16:1 fatty acids.
\end{abstract}

\section{Introduction}

Previous studies revealed that the growth and survival of Staphylococcus aureus within abscesses is controlled by the production of two types of bactericidal lipid. ${ }^{1-3}$ One consists of a pool of long-chain unsaturated free fatty acids and the other is a heretofore unidentified lipid with unique properties. ${ }^{2,3}$ The lipid differed from the fatty acids in that it has a greater specific activity, ${ }^{2}$ exhibits differential activity ${ }^{2}$ and its activity is reduced by oxidation. ${ }^{4}$ The bactericidal activity of both types of lipid is destroyed by an esterifying enzyme (FAME) which is produced by most strains of $S$. aureus and which appears to be necessary if the organism is to survive in the tissues. ${ }^{5}$ During our attempt to identify the lipid, it was found that incubation of staphylococcal abscess homogenates with the calcium ionophore A23187 resulted in a marked increase in the amount of the lipid in the preparation and this facilitated its isolation and identification.

Received 18 June 1991; revised version accepted 20 Jan. 1992. * Present address: Department of Clinical Pathology, National Institutes of Health, Bethesda, MD 20892, USA.

$\dagger$ Correspondence should be sent to Professor F. A. Kapral, Department of Medical Microbiology, The Ohio State University, 333 West 10th Avenue, Columbus, OH 43210-1239, USA.

\section{Materials and methods}

\section{Animals}

Sprague-Dawley Swiss White ICR female mice (Harlan Laboratories, Indianapolis, IN, USA) were used throughout these studies.

\section{S. aureus strains}

$S$. aureus strain $18 \mathrm{Z}$ was used to generate intraperitoneal abscesses. ${ }^{6}$ For routine assay of bactericidal activity, strain 303 was used as the indicator organism. ${ }^{1}$ To demonstrate differential activity, samples were assayed with $S$. aureus strains TG and 303., ${ }^{2,3}$ These represent strains with low and high sensitivity to the unidentified bactericidal lipid, respectively.

\section{Preparation of abscess homogenates}

Groups of 5-10 mice weighing 25-35 g were inoculated intraperitoneally with $10^{9} \mathrm{cfu}$ of $S$. aureus strain $18 \mathrm{Z}$ in a volume of $0.25 \mathrm{ml}^{6}$ After 7 days, the animals were killed and the abscesses were harvested, taking care not to include any extraneous host tissue. The abscesses from several mice were pooled and homogenised in saline with a motor-driven teflon pestle in a glass mortar. ${ }^{3}$ Homogenates were sealed in ampoules and stored at $-70^{\circ} \mathrm{C}$. 


\section{Preparation of lipid extracts}

Lipids were extracted from abscess homogenates by the method of Dole and Meinertz. ${ }^{7}$ The lipids were dissolved in ethanol and stored at $-20^{\circ} \mathrm{C}$ until needed.

\section{Bactericidal assay}

Abscess homogenates were first heated at $80^{\circ} \mathrm{C}$ for $30 \mathrm{~min}$ to eliminate the residual staphylococci present in the abscesses. Using $S$. aureus strains TG or 303 as the indicator organisms, bactericidal activity was measured as previously described. ${ }^{2}$ Each assay was done in duplicate.

A bactericidal unit was defined as that amount of homogenate or lipid extract that destroyed $50 \%$ of the indicator staphylococci in $1 \mathrm{~h}$. The concentration of bactericidal activity was expressed as $\mathrm{LD} 50 / \mathrm{ml}$ of homogenate or $\mathrm{LD} 50 / \mathrm{mg}$ of lipid.

\section{Thin layer chromatography}

Extracted lipids were separated by chromatography on Silica Gel G-coated glass plates. Before use, plates were washed in ether-methanol $(10: 1, \mathrm{v}: \mathrm{v})$, dried, and activated at $100^{\circ} \mathrm{C}$ for $30 \mathrm{~min}$. After spotting, the plates were developed in a single direction in the appropriate solvent system. After drying in air, the lipids were visualised by exposure to iodine vapour or by spraying the plate with aqueous sulphuric acid $50 \%$ containing potassium dichromate $0.6 \%$ and then charring at $180^{\circ} \mathrm{C}$ for $60 \mathrm{~min}$.

\section{Recovery of lipids after TLC}

Lipid spots visualised by iodine were recovered by scraping the silica gel and extracting three times with ethyl ether:methanol $(10: 1, \mathrm{v}: \mathrm{v})$. The pooled extracts were dried under nitrogen, weighed, dissolved in ethanol or hexane, and stored at $-20^{\circ} \mathrm{C}$ until needed.

\section{Hydrolysis of acyl glycerols}

The procedure for hydrolysis of acyl glycerols has been described. ${ }^{8}$ Briefly, to a $50-\mu \mathrm{g}$ lipid sample in $50 \mu \mathrm{l}$ of hexane was added $0.1 \mathrm{ml}$ of $0.05 \mathrm{~N}$ tetraethylammonium hydroxide in ethanol (tetraethylammonium hydroxide $10 \%$ diluted $1: 14 \mathrm{v}: \mathrm{v}$ in ethanol). The contents were heated at $60^{\circ} \mathrm{C}$ for $30 \mathrm{~min}$, and while still in the water bath, $0.1 \mathrm{ml}$ of $0.1 \mathrm{~N} \mathrm{HCl}$ was added. The contents were mixed and $1.8 \mathrm{ml}$ of water was added. The free fatty acids were removed by extracting three times with $1.5 \mathrm{ml}$ of hexane and combining the upper hexane phases; glycerol remained in the aqueous phase.

\section{Glycerol determination}

The determination of glycerol was based on the formation of formaldehyde through the oxidation of glycerol with sodium periodate. ${ }^{9,10}$ The formaldehyde was then allowed to react with chromotropic acid in a sulphuric acid solution, and the resultant violetcoloured product was determined spectrophotometrically by recording the absorbance at $570 \mathrm{~mm}$.. The unknown was compared with a standard curve prepared with $0 \cdot 2-1.0 \mu \mathrm{mol}$ of glycerol.

\section{Esterification of the bactericidal lipid by FAME}

A $100-200-\mu \mathrm{g}$ sample of bactericidal lipid (or monoglyceride) dissolved in hexane was dispensed into a lipid-clean vial and the hexane was evaporated under nitrogen. To the vial was added $50 \mu$ of ethanol and $0.45 \mathrm{ml}$ of $0.01 \mathrm{M}$ sodium phosphate buffer (pH 6.0) containing $2.0 \mathrm{mg}$ of partially purified FAME. ${ }^{5,11}$ The mixture was incubated at $37^{\circ} \mathrm{C}$ for $1 \mathrm{~h}$ in a water bath with constant agitation. After incubation, the lipids were extracted twice with 2-ml volumes of ethyl ether:methanol $(6: 1, v: v)$ and once with $2 \mathrm{ml}$ of ethyl ether. The upper ether phases were combined and evaporated to dryness under nitrogen. The extracted lipids were dissolved in $50 \mu \mathrm{l}$ of hexane, and the entire amount was spotted on a silica gel Gcoated plate and chromatographed in a solvent system of petroleum ether:ethyl ether:acetic acid (40:60:1, $\mathrm{v}: \mathrm{v}: \mathrm{v})$. The appearance of a fatty acid ester spot was taken as evidence of FAME activity. ${ }^{5}$

\section{$\delta$ Toxin}

$S$. aureus $\delta$ toxin was prepared and assayed as described previously. ${ }^{12}$

\section{Chemicals}

Myo-inositol, myo-inositol 1,4,5-triphosphate and guanosine- $3^{\prime}, 5^{\prime}$-cyclic phosphate (cyclic GMP) were obtained from Calbiochem, San Diego, CA, USA. Tetraethylammonium hydroxide was from Eastman Kodak Co., Rochester, NY, USA. Chromotropic acid sodium salt was from Fisher Scientific Co., Pittsburgh, PA, USA. All other chemicals and lipid standards were obtained from Sigma.

\section{Solvents}

All solvents used were of reagent or HPLC grade, and those used for extraction of lipids were redistilled just before use.

\section{Results}

\section{Generation of bactericidal activity}

When abscess homogenates were incubated with $10 \mu \mathrm{M}$ calcium ionophore A23187, there was an increase in the amount of bactericidal activity (table I) and when these preparations were extracted by the 
Table I. Bactericidal activity of abscess homogenates (AH) after incubation with calcium ionophore A23187

\begin{tabular}{cc}
\hline Preparation & LD50/ml \\
\hline AH & 130 \\
AH $+10 \mu \mathrm{M} \mathrm{A23187}$ & 1260 \\
$10 \mu \mathrm{M} \mathrm{A23187} \mathrm{(control)}$ & 0 \\
\hline
\end{tabular}

Incubation was for $20 \mathrm{~min}$ at $37^{\circ} \mathrm{C}$.

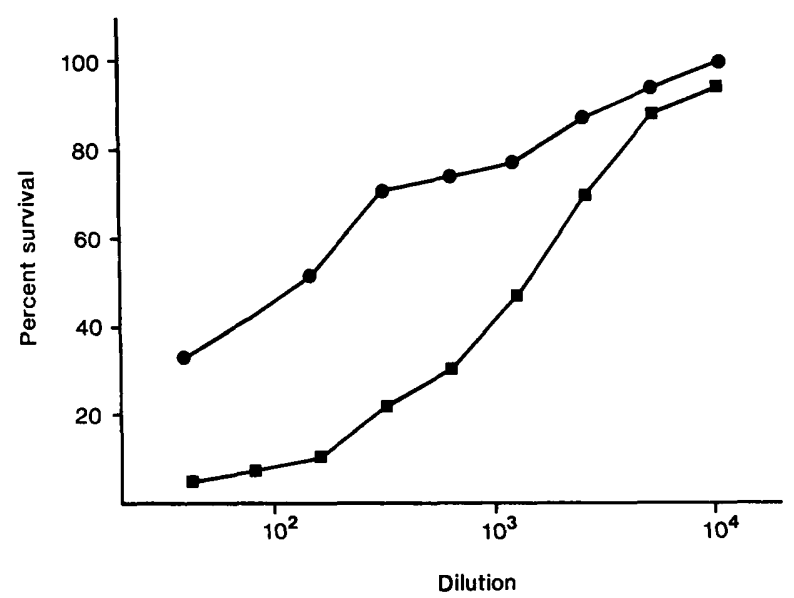

Fig. 1. Bactericidal activity of lipids extracted from untreated abscess homogenates (-) or from abscess homogenates treated with $10 \mu \mathrm{M}$ calcium ionophore A23187 ( $\square-\square$ ) for $20 \mathrm{~min}$. Indicator strain was $S$. aureus 303.

Table II. Bactericidal activity generated in abscess homogenates $(\mathrm{AH})$ by calcium ionophores

\begin{tabular}{lc}
\hline Preparation & LD50/ml \\
\hline $\mathrm{AH}$ & 1600 \\
$\mathrm{AH}+1 \mu \mathrm{M} \mathrm{A23187}$ & 1900 \\
$\mathrm{AH}+10 \mu \mathrm{M}$ A23187 & 3600 \\
$\mathrm{AH}+100 \mu \mathrm{M}$ A23187 & 3100 \\
$\mathrm{AH}+10 \mu \mathrm{M}$ Lasalocid & 1600 \\
$\mathrm{AH}+100 \mu \mathrm{M}$ Lasalocid & 2500 \\
$100 \mu \mathrm{M}$ A23187 (control) & 0 \\
$100 \mu \mathrm{M}$ Lasalocid (control) & 0 \\
\hline
\end{tabular}

Incubation was for $50 \mathrm{~min}$ at $37^{\circ} \mathrm{C}$.

method of Dole and Meinertz ${ }^{7}$ all the bactericidal activity resided in the lipid fraction. This change in bactericidal activity was accompanied by an increase in the slope of the dose-response curve (fig. 1), indicating the formation of a new compound. With extended incubation of abscess homogenates with A23187 the bactericidal activity continued to increase during the first $5 \mathrm{~h}$, but then diminished with further incubation. A concentration of $10 \mu \mathrm{M} \mathrm{A23187}$ was sufficient to generate maximum bactericidal activity (table II). However, the increase in bactericidal lipid over baseline levels differed among abscess homogenates in the range 2-37-fold (average 8-fold). Generally, the mean fold increase in bactericidal activity induced by A23187 was inversely proportional to the $\log$ of the baseline level in the homogenate.
Lasalocid, another calcium ionophore, increased the bactericidal lipid when used at a concentration of $100 \mu \mathrm{M}$, but the extent of this increase was only c. 70\% of that obtained with A23187 (table II). Nonactin and valinomycin, both potassium ionophores, and phorbol myristate acetate had no such effect on abscess homogenates. The addition of $10 \mathrm{~mm} \mathrm{Ca}{ }^{++}$had no stimulatory effect.

Pre-treatment of homogenates with $10 \mu \mathrm{M}$ verapamil, a calcium channel blocker, inhibited the ability of A23187 to generate the bactericidal lipid.

\section{Partial identification of the unknown lipid}

Total lipids extracted from either untreated abscess homogenates or from homogenates incubated with $10 \mu \mathrm{M} \mathrm{A} 23187$ for $200 \mathrm{~min}$ were examined by chromatography on silica gel G-coated plates with a solvent system of petroleum ether:ethyl ether:acetic acid (30:70:1, v:v:v). A very polar lipid was detected which was present in only small amounts in untreated homogenates, but was markedly increased in amount after incubation with A23187. The intensity of the spot appeared to depend upon the length of incubation with the ionophore.

Identification of the newly discovered polar lipid was attempted by spraying the TLC plates with various detection reagents. These included those used to detect phosphate, ${ }^{13}$ the carbohydrate of glycolipids, ${ }^{14}$ free amino groups, ${ }^{15}$ choline,${ }^{16}$ the sialic acid of gangliosides $^{17}$ and the amide group of sphingolipids. ${ }^{18}$ The unidentified lipid did not react with any of these reagents.

The presence of carbohydrates or sphingosines could not be detected by reaction with anthrone or trinitrobenzenesulphonic acid, respectively, with methods described previously. ${ }^{19}$

Subsequent studies showed that the unidentified lipid migrated to the same location as monoacylglycerides on thin-layer plates. When chomatographed with various solvent systems, including petroleum ether:ethyl ether:acetic acid (30:70:1, v:v:v), ethyl ether: acetone $(8: 2, \mathrm{v}: \mathrm{v})$, chloroform : methanol : water (80:10:2 and 65:25:4,v:v:v), and chloroform $100 \%$, the $R_{\mathrm{f}}$ of the unidentified lipid was identical to that of mono-oleoyglycerol or monopalmitoyglycerol. The unidentified lipid was confirmed as a glyceride by hydrolysing it and quantifying the glycerol released. A $50-\mu \mathrm{g}$ sample recovered from thin-layer plates yielded $17 \mu \mathrm{g}(0.185 \mu \mathrm{mol})$ of glycerol. This amounted to $34 \%$ glycerol in the sample, which was reasonably close to the amount present in monoglycerides such as monopalmitolein or monopalmitin ( $28 \%$ glycerol).

\section{Characterisation of the monoglyceride}

Lipids recovered from abscess homogenates treated with A23187 were chromatographed on silica gel Gcoated plates with petroleum ether:ethyl ether:acetic acid (30:70:1, v:v:v). The various lipid spots were 


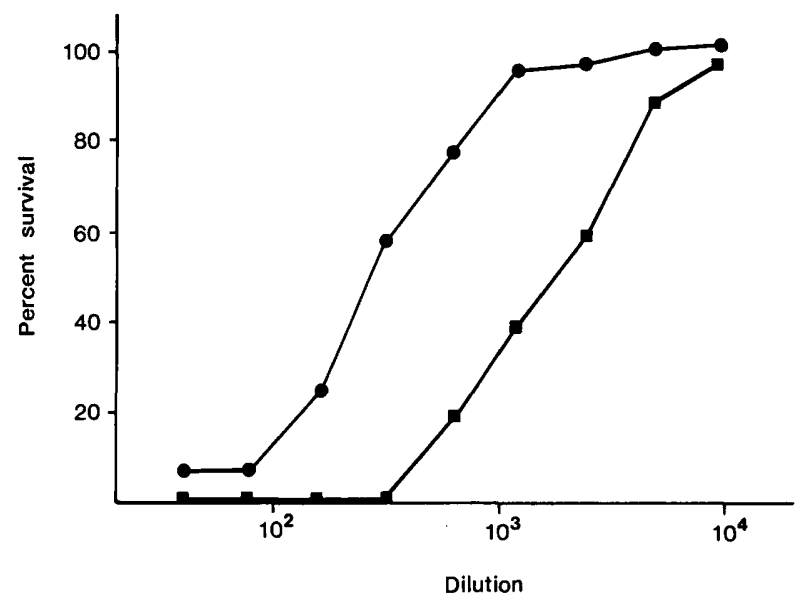

Fig. 2. Dose-response curves showing differential bactericidal activity of the monoglyceride for strain TG (O-O) $\left(2.76 \times 10^{2}\right.$ $\mathrm{ED} 50 / \mathrm{mg})$ and $303(\mathrm{D}-\mathrm{C})\left(1.55 \times 10^{3} \mathrm{ED} 50 / \mathrm{mg}\right)$.

recovered from the plate and were assayed for bactericidal activity against the two $S$. aureus indicator strains, TG and 303. Whereas the monoglyceride fraction possessed a high specific activity against strain 303 , the other lipids possessed little or no activity. Furthermore, the monoglyceride manifested differential activity as evidenced by its greater activity against strain 303 than against strain TG (fig. 2).

To determine whether the monoglyceride was sensitive to oxidation, samples of a solution in ethanol were stored in sealed ampoules under either oxygen or nitrogen. After $48 \mathrm{~h}$ at room temperature, both samples were assayed for residual bactericidal activity. The activity of the monoglyceride was reduced by $75 \%$ in oxygen, but was unchanged under nitrogen. This is similar to the oxygen lability of the unidentified lipid.

Since the unidentified lipid was known to be neutralised by $S$. aureus $\delta$ toxin, lecithin and calcium, the monoglyceride was examined for its sensitivity to these substances. In each case, when the monoglyceride was mixed with the substance and assayed for residual bactericidal activity, a reduction in activity was noted (table III).

\section{The effect of FAME on the monoglyceride}

The fatty acid modifying enzyme (FAME) produced by most $S$. aureus strains had been found to esterify both the unidentified lipid and the bactericidal fatty

Table III. Inhibition of monoglyceride by $\delta$ toxin, lecithin or calcium

\begin{tabular}{lc}
\hline Preparation & LD50/mg \\
\hline Monoglyceride & 1850 \\
Monoglyceride $+20 \mu \mathrm{g} \delta$ toxin & 100 \\
Monoglyceride $+20 \mu \mathrm{g}$ lecithin & 110 \\
Monoglyceride & $1400^{*}$ \\
Monoglyceride $+200 \mu \mathrm{g} \mathrm{Ca}^{++}$ & $700^{*}$
\end{tabular}

* Assayed in saline instead of the usual diluent. acids, thereby destroying their bactericidal activities. ${ }^{5}$ Incubation of a $120-\mu \mathrm{g}$ sample of the monoglyceride with FAME and ethanol, and subsequent TLC of the extracted lipids showed that the acyl group from the monoglyceride had been esterified to ethanol.

\section{Effect of the calcium ionophore A23187 on abscess homogenate fractions}

Abscess homogenates were centrifuged at $39000 \mathrm{~g}$ for $30 \mathrm{~min}$ and divided into a cell-free supernatant fraction and a sediment fraction. The sediment fraction was washed three times in saline and resuspended in the original volume of saline. Each fraction, either separate or combined, was assayed for bactericidal activity before and after the addition of $10 \mu \mathrm{M}$ A23187. As previously noted, all the bactericidal activity present before treatment was found to reside in the sediment. ${ }^{1}$ When A23187 was added to each individual fraction, no additional activity was generated. However, when both fractions were recombined, A23187 was able to increase the bactericidal activity by production of the monoglyceride.

The addition of $10 \mu \mathrm{M}$ A23187 to abscess homogenate previously heated to $100^{\circ} \mathrm{C}$ for $30 \mathrm{~min}$ failed to generate any increase in bactericidal activity. Furthermore, A23187 had no effect on the bactericidal activity of the total lipid fraction or the monoglyceride fraction already extracted from abscess homogenates (table IV).

\section{Inositol triphosphate involvement in monoglyceride production}

Since calcium ionophores are known to mimic the action of the second messenger inositol triphosphate, ${ }^{20}$ which functions to release calcium from internal stores, we evaluated whether this second messenger might be involved in the synthesis of the monoglyceride. Accordingly, $10 \mu \mathrm{M}$ inositol triphosphate was incubated with samples of abscess homogenate for $50 \mathrm{~min}$ at $37^{\circ} \mathrm{C}$, and the bactericidal activity of the preparation was assayed. Inositol triphosphate increased the bactericidal activity of homogenates to an extent similar to that obtained with A23187. A time course study demonstrated that when abscess homogenate was treated with $10 \mu \mathrm{M}$ inositol triphosphate, the bactericidal activity continued to increase for at least $22 \mathrm{~h}$ (fig. 3).

Table IV. Effect of calcium ionophore A23187 on the bactericidal activity of the total lipid fraction of the monoglyceride extracted from abscess homogenates

\begin{tabular}{lc}
\hline Preparation & LD50/mg \\
\hline Total lipids & 380 \\
Total lipids $+10 \mu \mathrm{M} \mathrm{A23187}$ & 370 \\
Monoglyceride & 1820 \\
Monoglyceride $+10 \mu \mathrm{M} \mathrm{A23187}$ & 2250 \\
\hline
\end{tabular}

Incubation was for $50 \mathrm{~min}$ at $37^{\circ} \mathrm{C}$. 


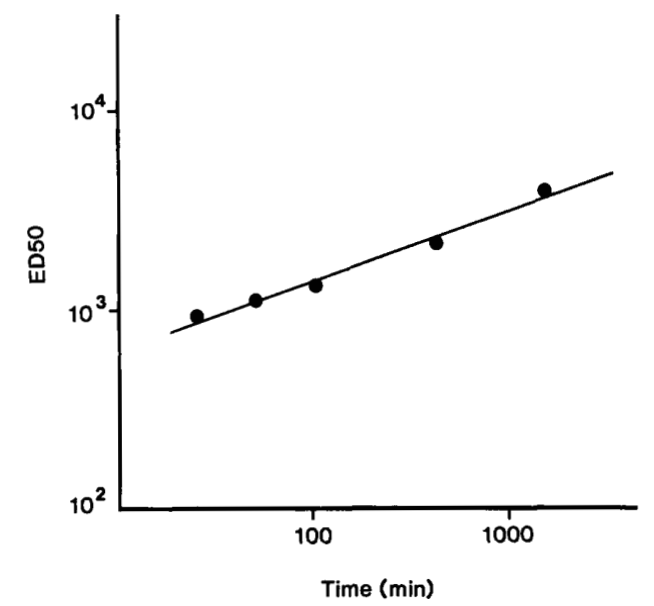

Fig. 3. Generation of bactericidal activity (ED50/ml) in abscess homogenates treated with $10 \mu \mathrm{M}$ inositol triphosphate and incubated at $37^{\circ} \mathrm{C}$; indicator strain was $S$. aureus 303 .

However, phosphatidylinositol 4,5-biphosphate, the source of inositol triphosphate in vivo, or inositol did not affect the bactericidal activity. Similarly, cyclic GMP, a second messenger known to activate the Gkinase, did not alter the bactericidal activity in homogenates.

\section{Monoglyceride production in other tissues}

To determine whether the monoglyceride is produced in tissues other than abscesses, the spleen, kidney, liver, heart, brain, lung or skeletal muscle was removed from either normal mice or from mice given $10^{9} \mathrm{cfu}$ of $S$. aureus intraperitoneally 7 days earlier. Each tissue sample was homogenised in saline. Lipid extracts from untreated tissue homogenates or from tissue homogenates incubated for $200 \mathrm{~min}$ at $37^{\circ} \mathrm{C}$ with $10 \mu \mathrm{M}$ calcium ionophore A23187, were spotted on silica gel G-coated plates and developed in a solvent system of petroleum ether:ethyl ether:acetic acid (30:70:1, v:v:v). A sample of monoglyceride derived from abscess homogenate was run as a control. No monoglyceride spot could be found in the extracts from any of the tissues, suggesting that the monoglyceride production is unique to staphylococcal abscesses, as found with the unidentified lipid.

The tissue homogenates were incubated for $50 \mathrm{~min}$ at $37^{\circ} \mathrm{C}$ after the addition of $10 \mu \mathrm{M}$ inositol triphosphate. Again, no monoglyceride was found in any of the samples.

\section{Comparison of monoglycerides}

To determine which positional isomer of monoglyceride was being generated in abscess homogenate treated with calcium ionophore A23187, the monoglyceride fraction was isolated and immediately spotted on fresh silica gel $G$ plates. The plates were promptly developed in benzene:ethyl acetate:trimethyl borate $(100: 20: 7 \cdot 2$, v:v:v) to separate the 1-monoglycerides and 2-monoglycerides. In this solvent system, the borate is provided to prevent
Table V. Bactericidal activity of various glycerides against S. aureus strains TG and 303

\begin{tabular}{ccc}
\hline & \multicolumn{2}{c}{ LD50/mg against } \\
\cline { 2 - 3 } Lipid & TG & 303 \\
\hline 1-Mono-olein & 1930 & 2880 \\
2-Mono-olein & 1940 & 5510 \\
1,2-Diolein & $<10$ & $<10$ \\
1,3-Diolein & $<10$ & $<10$ \\
Triolein & $<10$ & $<10$ \\
\hline
\end{tabular}

Table VI. Fatty acid composition of monoglycerides recovered from abscess homogenates treated with calcium ionophore A23187

\begin{tabular}{cc}
\hline Fatty acid & Composition $(\%)^{*}$ \\
\hline $14: 0$ & $0 \cdot 63$ \\
$14: 1$ & $4 \cdot 47$ \\
$16: 0$ & $20 \cdot 73$ \\
$16: 1$ & $69 \cdot 11$ \\
$18: 0$ & $3 \cdot 43$ \\
$18: 1$ & $0 \cdot 35$ \\
$18: 3$ & $0 \cdot 58$ \\
Total & $99 \cdot 40$ \\
\hline
\end{tabular}

* Average of three determinations.

migration of the acyl group during chromatography. ${ }^{21}$ The 2-monoglyceride was the major isomer produced during ionophore treatment, although some 1monoglyceride was also present.

To evaluate the effect that acyl group position might have on bactericidal activity, a series of related oleyl glycerides was obtained from commercial sources and tested for activity against $S$. aureus strains TG and 303. Although both monoglycerides possessed significant bactericidal activity, the 2-mono-olein expressed the greatest degree of differential activity (table V). In contrast, the dioleins and triolein had no demonstrable activity against either organism.

\section{Fatty acid composition of monoglycerides}

A sample of monoglyceride was recovered from homogenates treated with $10 \mu \mathrm{M}$ A23187 and was hydrolysed with tetraethylammonium hydroxide. The free fatty acids were extracted with hexane, methylated with diazomethane ${ }^{22}$ and quantified by gas chromatography. Palmitoleic acid accounted for $c .69 \%$ of the fatty acid moieties in the monoglyceride and palmitic acid for c. $21 \%$ (table VI). Smaller amounts of $\mathrm{Cl} 4$ and $\mathrm{C} 18$ fatty acids were also present.

\section{Discussion}

The realisation that staphylococcal abscesses contained two distinct types of bactericidal lipid was based upon the observation that total lipid extracts of abscesses exhibited differential activity, whereas the isolated free fatty acid pool did not. ${ }^{2,3}$ Differential 
activity was defined as the ability of the lipid to kill certain $S$. aureus indicator strains more readily than others, yet these same strains were of equal sensitivity to the free fatty acids. ${ }^{3}$ Attempts to isolate the lipid possessing differential activity by means of silicic acid column chromatography were unsuccessful because of the instability of the unidentified lipid. The only fraction recovered that exhibited bactericidal activity was the free fatty acid fraction, and this did not possess differential activity. ${ }^{2}$

Subsequently, other characteristics were detected that distinguished the unidentified lipid from the bactericidal fatty acids. ${ }^{4}$ The lipid has a greater specific activity and it is uniformly active over pH 5.5-9.0. In contrast to the fatty acids, it is not affected by hydrogenation, but its activity is destroyed by oxidation. It also became evident that whereas the fatty acids collectively comprise about $40 \%$ of the total lipid in abscesses, the unidentified lipid accounts for $<0.1 \%$.

In view of the low levels and lability of the unidentified lipid, consideration was given to the possibility that it might be an intermediate leading to the synthesis of eicosanoids such as prostaglandins or leukotrienes. Accordingly, abscess homogenates were treated with substances that would increase eicosanoid production. One of these, calcium ionophore A23187, did increase the amount of a bactericidal lipid which possessed all the properties of the unidentified lipid. However, when other compounds known to inhibit prostaglandin and leukotriene synthesis were also added to the homogenates, they failed to inhibit the action of A23187. This indicated that although the ionophore stimulated the production of the lipid, it was not an eicosanoid. Subsequent studies revealed that it was a monoglyceride.

Whereas small amounts of monoglycerides were usually present in abscess homogenates before treatment, the amounts were increased substantially after incubation with ionophore. The degree of increase was inversely proportional to the logarithm of the amount of monoglyceride originally present. In other words, the greatest increases induced by the ionophore were seen in homogenates that had low monoglyceride levels before treatment.

Monoglyceride synthesis was also stimulated by the calcium ionophore Lasalocid, but not by the potassium ionophores nonactin or valinomycin, or by phorbol myristate acetate. However, the effect of A23187 was prevented by the calcium channel blocker, verapamil.

Our data suggest that the 2-monoglyceride is synthesised in abscess homogenates, but that this quickly isomerises to form the 1-monoglyceride. The speed and extent of isomerisation of monoglycerides depends upon the particular fatty acid in the molecule and the environmental conditions such as temperature and $\mathrm{pH} .{ }^{23}$ Although both isomers are bactericidal, the 2monoglyceride exhibits greater differential activity (table V).
In retrospect, it appears that the reason we had not detected the bactericidal monoglyceride during our previous studies was because we had fractionated the lipids by column chromatography and the solvent systems offered no protection against isomerisation. ${ }^{21}$ During the 3-4 days required for fractionation, the small amounts of 2-monoglycerides originally present in the abscesses would have isomerised and then degraded into free fatty acid and glycerol. The small amounts of resultant fatty acid would simply have been included in the free fatty acid fraction and would no longer have possessed any distinguishing characteristics.

The 2-monoglyceride exhibited all the properties previously attributed to the unidentified lipid. It had a high specific activity and the same degree of differential activity (table V, fig. 2). Its bactericidal activity was neutralised by $\mathrm{Ca}^{++}$, lecithin and $S$. aureus $\delta$ toxin (table III) and was destroyed by oxidation or exposure to $S$. aureus FAME.

Inositol 1,4,5-triphosphate (IP3) could substitute for calcium ionophore in stimulating monoglyceride synthesis in abscess homogenates. This suggested that release of calcium from intracellular stores is required for monoglyceride production. However, this process did not result in the formation of free fatty acids. Of all the components of the IP3 cycle, ${ }^{20,24,25}$ only IP3 stimulated monoglyceride production.

Addition of A23187 to either the cell-free supernatant fraction of abscess homogenate or the washed sediment did not result in the production of monoglyceride. However, production of monoglyceride was seen when the ionophore was added to the recombined fractions. This suggests that some soluble substance(s) in the supernate must act in concert with membranous components to synthesise the monoglyceride. Whether the soluble substance is an enzyme, calmodulin, or some other substance is not yet known.

Monoglyceride was produced in abscess homogenates treated with calcium ionophore or IP3, but not in similarly treated homogenates of other tissues from normal mice or infected mice. Since mature abscesses contain only neutrophils, macrophages and connective tissue cells, ${ }^{6}$ all of which are found in other tissues, this suggests that some additional priming event is necessary before monoglyceride synthesis can proceed. It is possible that this primary event involves changes induced by the inflammatory response or by cytokines induced during infection.

The fatty acid moiety of the monoglyceride pool consists primarily of palmitoleic acid and palmitic acid (table VI), whereas the pool of free fatty acids produced in abscesses is composed of mainly oleic and palmitic acids, with smaller amounts of palmitoleic and linoleic acids. ${ }^{2}$ This is in keeping with the view that these two types of bactericidal lipid arise from different sources and through different mechanisms.

This investigation was supported by Public Health Service grant AI-19879 from the National Institute of Allergy and Infectious Disease. 


\section{References}

1. Dye ES, Kapral FA. Survival of Staphylococcus aureus in intraperitoneal abscesses. J Med Microbiol 1981; 14: 185-194.

2. Dye ES, Kapral FA. Characterization of a bactericidal lipid developing within staphylococcal abscesses. Infect Immun 1981; 32 : 98-104.

3. Dye ES, Kapral FA. Partial characterization of a bactericidal system in staphylococcal abscesses. Infect Immun 1980; 30: 198-203.

4. Kapral FA, Mortensen JE. Mechanisms of resistance to staphylocidal fatty acids in abscesses. In: Jeljaszewicz J (ed) The staphylococci. Zentralbl Bakteriol Suppl 14. Stuttgart, Gustav Fischer Verlag. 1985: 507-509.

5. Mortensen JE, Shryock TR, Kapral FA. Modification of bactericidal fatty acids by an enzyme of Staphylococcus aureus. J Med Microbiol 1992; 36: 293-298.

6. Kapral FA, Godwin JR, Dye ES. Formation of intraperitoneal abscesses by Staphylococcus aureus. Infect Immun 1980; 30: 204-211.

7. Dole VP, Meinertz H. Microdetermination of long-chain fatty acids in plasma and tissues. $J$ Biol Chem 1960; 235: 2595-2599.

8. Chernick SS. Determination of glycerol in acyl glycerol. In: Lowenstein JM (ed) Methods in enzymology, vol. XIV, Lipids. New York, Academic Press. 1969: 627-630.

9. Lambert M, Neish AC. Rapid method for estimation of a glycerol in fermentation solutions. Cand $J$ Res, Sect B $1950 ; 28$ : 83-89.

10. Hanahan DJ, Olley JN. Chemical nature of monophosphoinositides. J Biol Chem 1958; 231 : 813-828.

11. Kapral FA, Smith S, Lal D. The esterification of fatty acids by Staphylococcus aureus fatty modifying enzyme (FAME) and its inhibition by glycerides. J Med Microbiol $1992 ; 37$ : 235-237.

12. Nolte FS, Kapral FA. Hydrophobic interaction chromato- graphy of Staphylococcus aureus delta-toxin. Infect Immun 1981; 31: 1094-1098.

13. Vaskovsky VE, Kostetsky EY. Modified spray for the detection of phospholipids on thin-layer chromatograms. J Lipid Res 1968; 9: 396.

14. Svennerholm $\mathrm{L}$. The quantitative estimation of cerebrosides in nervous tissue. $J$ Neurochem 1956 ; 1 : 42-53.

15. Skipski VP, Peterson RF, Barclay M. Separation of phosphatidyl ethanolamine, phosphatidyl serine, and other phospholipids by thin-layer chromatography. $J$ Lipid Res 1962; 3: 467-470.

16. Christie WW. Lipid analysis, 2nd edn. Oxford, Pergamon Press. 1982: 120 .

17. Svennerholm L. Quantitative estimation of sialic acids. II. A colorimetric resorcinol-hydrochloric acid method. Biochim Biophys Acta 1957; 24: 604-611.

18. Bischel MD, Austin JH. A modified benzidine method for the chromatographic detection of sphingolipids and acid polysaccharides. Biochim Biophys Acta 1963; 70: 598-600.

19. Yamamoto A, Rouser G. Spectrophotometric determination of molar amounts of glycosphingolipids and ceramide by hydrolysis and reaction with trinitrobenzenesulfonic acid. Lipids 1970; 5: 442-444.

20. Berridge MJ. The molecular basis of communication within the cell. Sci Am 1985; 253 (4):124-134.

21. Pollack JD, Clark DS, Somerson NL. Four-directionaldevelopment thin-layer chromatography of lipids using trimethyl borate. $J$ Lipid Res 1971 ; 12 : 563-569.

22. Fales HM, Jaouni TM, Babashak JF. Simple device for preparing ethereal diazomethane without resorting to codistillation. Anal Chem 1973; 45: 2302-2303.

23. Mattson FH, Volpenhein RA. Synthesis and properties of glycerides. J Lipid Res 1962; 3: 281-296.

24. Berridge MJ. Inositol triphosphate and diacylglycerol as second messengers. Biochem $J$ 1984; 220 : 345-360.

25. Berridge MJ, Irvine RF. Inositol triphosphate, a novel second messenger in cellular signal transduction. Nature 1984; 312: 315-321. 